\title{
CARACTERIZAÇÃO DA MADEIRA POR ULTRASSOM POR MEIO DE CORPO DE PROVA POLIÉDRICO COM NÚMERO REDUZIDO DE FACES.
}

\author{
João Pedro de Oliveira Ferreira*, Geise Aparecida Pereira, Cinthya B. Pedroso.
}

\section{Resumo}

O conhecimento das propriedades elásticas da madeira é fundamental para sua adequada aplicação. O corpo de prova poliédrico com 26 faces, utilizado na caracterização completa da madeira por ultrassom, já está bem estabelecido, porém os valores obtidos para os coeficientes de Poisson apresentam algumas divergências. Sendo assim, este projeto de iniciação científica teve como objetivo a caracterização completa da madeira por ultrassom utilizando corpos de prova poliédrico com número reduzido de faces. Os resultados obtidos para os parâmtros elásticos para três especies de madeira mostraram que é possível utilizar o poliedro de 18 faces para caracterizar o material.

\section{Palavras-chave: Coeficiente de Poisson, constantes elásticas, módulo de elasticidade}

\section{Introdução}

A determinação das constantes elásticas da madeira (módulos de elasticidade longitudinais nas diferentes direções, módulos de elasticidade tangenciais nos diferentes planos e coeficientes de Poisson) é imprescindível para o conhecimento das propriedades da mesma e, portanto, para sua adequada aplicação. O grupo de pesquisa do Laboratório de Ensaios Não Destrutivos (LabEND) da Faculdade de Engenharia Agrícola (FEAGRI) da Universidade Estadual de Campinas (UNICAMP), já adotou metodologia e geometria de corpos de prova para o ensaio de caracterização por ultrassom da madeira. Os resultados mostram que esta geometria apresenta bons resultados para a determinação dos módulos de elasticidade longitudinais e de cisalhamento, mas alguns dos coeficientes de Poisson apresentam muitas inconsistências quando comparados com valores esperados. Visando melhorar a precisão dos resultados dos parâmetros elásticos, a pesquisa teve por objetivo a caracterização completa da madeira por ultrassom utilizando corpo de prova poliédrico com número reduzido de faces.

\section{Resultados e Discussão}

Os ensaios foram realizados com ultrassom (EP1000, Olympus, EUA) e transdutores de ondas longitudinais e de ondas transversais de faces planas e frequência de 1,0 $\mathrm{MHz}$. Três espécies de madeira (cedro rosa, garapeira e angelim vermelho) foram caracterizadas com poliedros de 18 faces, sendo que para cada espécie foram confeccionados 6 poliedros.

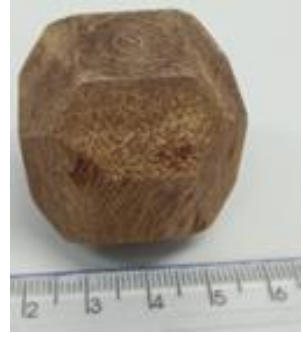

a

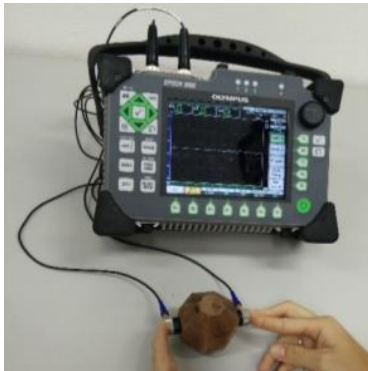

b
Figura 1. Poliedros de 18 faces (a) e ensaio de ultrassom no poliedro (b).
De posse dos dados de velocidade de propagação de ondas de ultrassom e da densidade de cada espécie, foi possível construir a matriz de rigidez utilizand as equações de Christoffel, invertendo a matriz de rigidez foi obtido a matriz de flexibilidade, sendo determinados os parâmetros elásticos das amostras avaliadas (Tabela 1).

Tabela 1. Módulos de elasticidade $\left(E_{L}, E_{R}, E_{T}\right)$, módulos de cisalhamento (GRT, GLT e $G_{L R}$ ) e coeficientes de Poisson nos planos (vRL, vTL, VLR, vTR, VLT, VRT).

\begin{tabular}{|c|c|c|c|c|c|c|}
\hline \multirow{2}{*}{$\begin{array}{c}\text { Parâmetros } \\
\text { elásticos }\end{array}$} & \multicolumn{2}{|c|}{ Cedro rosa } & \multicolumn{2}{|c|}{ Garapeira } & \multicolumn{2}{|c|}{$\begin{array}{c}\text { Angelim } \\
\text { vermelho }\end{array}$} \\
\hline & Média & CV (\%) & Média & CV (\%) & Média & CV (\%) \\
\hline $\mathrm{E}_{\mathrm{L}}(\mathrm{MPa})$ & 10945 & 38 & 17399 & 14 & 23254 & 12 \\
\hline$E_{R}(M P a)$ & 1765 & 34 & 3281 & 16 & 3496 & 17 \\
\hline $\mathbf{E}_{\mathrm{T}}(\mathrm{MPa})$ & 955 & 41 & 2199 & 11 & 2326 & 19 \\
\hline $\mathrm{G}_{\mathrm{RT}}(\mathrm{MPa})$ & 688 & 82 & 656 & 8 & 919 & 15 \\
\hline $\mathrm{G}_{\mathrm{LT}}(\mathrm{MPa})$ & 821 & 23 & 1274 & 5 & 1436 & 3 \\
\hline $\mathrm{G}_{\mathrm{LR}}(\mathrm{MPa})$ & 1131 & 16 & 1569 & 7 & 1687 & 3 \\
\hline $\mathbf{v}_{\mathrm{RL}}$ & 0,10 & 36 & 0,12 & 21 & 0,11 & 44 \\
\hline$v_{\text {TL }}$ & 0,07 & 70 & 0,10 & 21 & 0,06 & 55 \\
\hline$v_{L R}$ & 0,67 & 62 & 0,63 & 21 & 0,70 & 28 \\
\hline $\mathbf{v}_{\mathrm{TR}}$ & 0,36 & 14 & 0,20 & 51 & 0,37 & 44 \\
\hline$v_{L I}$ & 0,75 & 31 & 0,79 & 20 & 0,60 & 61 \\
\hline$y_{\mathrm{RT}}$ & 0,68 & 19 & 0,30 & 49 & 0,50 & 29 \\
\hline
\end{tabular}

Por meio da análise dos dados dos parâmetros elásticos apresentados da Tabela 1 , verifica-se que 0 levantamento das propriedades elásticas, também por ensaio estático, seria relevante, principalmente para verificação do elevado coeficente de variação dos módulos de elasticidade e de cisalhamento apresentados pelo cedro rosa.

\section{Conclusões}

A caracterização completa de três espécies de madeira foi possível utilizando poliedros com número reduzido de faces (18).

\section{Agradecimentos}

À Prof. Doutora Cinthya B. Pedroso pela orientação, à Geise Aparecida Pereira pela coorientação.

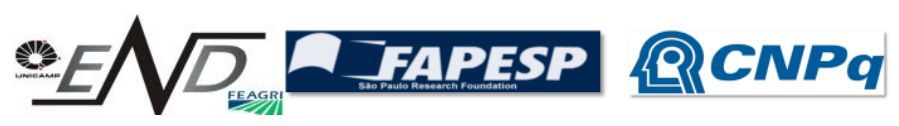

